\title{
Sustainability assessment of energy technologies: towards an integrative framework
}

\author{
Armin Grunwald ${ }^{*}$ and Christine Rösch
}

\begin{abstract}
To be able to design and use energy technologies with regard to the needs of sustainable development, sustainability assessments are necessary prior to the respective decisions. However, as is known, they pose methodological problems: from the difficulties of anticipation of future developments via the determination of assessment criteria through to the necessity to define sustainable development accurately enough. In this contribution, we will introduce an integrative sustainability concept which has hardly been discussed in the energy context. We will analyse this concept with respect to deriving general principles for the sustainability assessment of energy technologies. As a case study, we consider in particular the field of the use of grassland for biomass production for energetic purposes. The integrative concept is shown to provide an overall framework to carry out comprehensible and, above all, comparative sustainability assessments. More or less as a by-product, it can be demonstrated that sustainability means also in the energy sector much more than just environmental compatibility.
\end{abstract}

Keywords: energy futures, sustainability assessment, energy policy; grassland

\section{Energy technology assessment for energy policies}

The vision of sustainable development must by definition include both long-term considerations and the global dimension $[1,2]$. Pursuing this vision implies that societal processes and structures should be re-orientated so as to ensure that the needs of future generations are taken into account and to enable current generations in the southern and northern hemispheres to develop in a manner that observes the issues of equity and participation $[3,4]$. Since a feature inherent in the Leitbild of sustainable development is the consideration of strategies for shaping current and future society according to its normative content, guidance is necessary and the ultimate aim of sustainability analyses, reflections, deliberations and assessments. The latter should result, in the last consequence, in knowledge for action, and this knowledge should motivate, empower and support 'real' action and decision making [5].

In energy policy and energy research, decisions have to be made about the technologies and infrastructures

\footnotetext{
* Correspondence: armin.grunwald@kit.edu

Institute for Technology Assessment and Systems Analysis (ITAS), Karlsruhe Institute of Technology (KIT), Helmholtz Platz 1, 76344 EggensteinLeopoldshafen, Germany
}

that may be used to provide and convert energy in future times, some of which are very distant [6]. The core issues for energy policy and the orientation of energy research - e.g. statements about the gradual depletion of fossil energy sources and about the perspectives for the competitiveness of renewable energy sources, the formulation of climate goals based on avoiding $\mathrm{CO}_{2}$, the safeguarding of the supply of energy to the economy in the face of shifts in geopolitics, the potentials and risks of the hydrogen economy, the longterm considerations about the role of fusion technology - are made up in part of far-reaching assumptions about future developments. They are the 'energy futures' on the basis of which decisions are made. Energy technologies of different kinds are built into those energy futures. Prospective knowledge of consequences, prognoses of technical progress, expectations and fears, as well as aims are bundled together as 'futures' (e.g. in the form of energy scenarios), which serve to provide orientation today for pending decisions. Energy technology assessment on technology assessment in general cp. Grunwald 2009 [7] shall support today's decisions. In the case of 'contested futures' [8] or competing energy

any medium, provided the original work is properly cited. 
technologies, comparative sustainability assessments are required for guiding decision making.

However, these sustainability assessments are methodologically precarious $[9,10]$. They depend on assumptions about the future, assessment criteria, emphases and indicators as well as on available data and models with their respective assumptions $[6,11]$. In order to provide rational decision support, sustainability assessments in the energy context must by no means be subject to arbitrariness. Otherwise ideology and misuse of assessments for particular purposes are imminent.

This paper is intended as a contribution on the way to a rational, i.e. transparent and comprehensible framework for sustainability assessments in the energy context. Such a framework has to start with the disclosure of and an explanatory statement on the understanding of sustainability and has to make it fruitful using a series of reasonable steps for the assessment process. This is done with reference to the integrative concept of sustainable development [12], which has over the last years predominantly been used in debates and research on sustainable land use and sustainable urban development. However, it has hardly been applied in discussions on a permanently sustainable energy supply, a topic which has gained importance in recent years ("The integrative approach to sustainable development" section). This concept is taken as a normative basis to provide a first orientation regarding energy technologies and to derive guiding principles which can be used to develop assessment criteria and indicators ("Sustainability principles for energy technology assessment" section). The possible use of grassland for the production of biomass for energetic purposes is introduced to illustrate how the integrative concept can be applied to concrete cases in a comparative way ("Case study: sustainability assessment of energy production from grassland" section). The conclusions ("Conclusions" section) show that also in the energy sector the Leitbild of sustainability by far exceeds the requirements of environmental compatibility - a fact that has not yet become apparent compared to other fields of sustainability. As some sort of side effect, it becomes obvious that the debate on sustainability of the energy supply is often narrowed down to questions of security of supply and environmental compatibility in industrial countries.

\section{The integrative approach to sustainable development}

There is considerable need for orientation knowledge on how to fill the Leitbild of sustainable development with substance conclusively as soon as it is expected to guide the transformation of societal systems, e.g. the energy system. To gain practical relevance, some essential criteria have to be fulfilled: (1) a clear object relation, i.e. by definition it must be clear what the term applies to and what not, and which are the subjects to which assessments should be ascribed; (2) the power of differentiation, i.e. clear and comprehensible differentiations between 'sustainable' and 'non- or less sustainable' must be possible and concrete ascriptions of these judgements to societal circumstances or developments have to be made possible beyond arbitrariness; (3) the possibility to operationalise, i.e. the definition has to be substantial enough to define sustainability indicators, to determine target values for them and to allow for empirical 'measurements' of sustainability.

The integrative concept of sustainable development [12] claims to meet these criteria. It provides a theoretically well-founded approach to operationalise the Leitbild and an operable analytical tool for sustainability analyses both being applied so far in various research projects [13]. Based on the Brundtland report with its well-known sustainability definition and on essential documents of the sustainability debate, such as the Rio Declaration or the Agenda 21, the starting point of this concept are not the several dimensions of sustainability, but three constitutive elements (for details, see Kopfmüller et al. 2001, Chap. 4 [12]): (1) inter- and intragenerational justice, equal in weight; (2) the global perspective regarding goals and action strategies; and (3) an enlightened anthropocentric approach in the sense of the obligation of mankind to interact cautiously with nature out of a well-understood self-interest, referring for instance to long-term preservation of nature. Accepting these elements requires a comprehensive, integrative understanding and implementation of sustainable development, in particular because justice is a cross-dimensional issue.

These constitutive elements are operationalised in two steps: first, they were 'translated' into three general goals of sustainable development, partly based on the Planetary trust theory of Brown-Weiss [14], being the condition precedent to sustainability (Table 1):

- securing human existence,

- maintaining society's productive potential (comprising natural, man-made, human and knowledge capital),

- preserving society's options for development and action.

Conflicts of goals between rules can exist on different levels. First of all, it cannot be excluded that the formulated working hypothesis of a simultaneous satisfiability of all rules will be falsified. Undiminished population growth, for instance, could lead to such a falsification, if satisfaction of basic needs of the world population would not be possible without breaking, e.g. the natural resource related rules. Other conflict potentials can arise when the guiding principles are translated into concrete responsibilities of action for societal actors. In such 
Table 1 The substantial principles of sustainability

\begin{tabular}{|c|c|c|c|}
\hline Goals & Securing mankind's existence & Upholding society's productive potential & $\begin{array}{l}\text { Keeping options for development and } \\
\text { action open }\end{array}$ \\
\hline \multirow[t]{5}{*}{ Rules } & Protection of human health & Sustainable use of renewable resources & $\begin{array}{l}\text { Equal access to education, information and } \\
\text { an occupation }\end{array}$ \\
\hline & Securing the satisfaction of basic needs & Sustainable use of non-renewable resources & $\begin{array}{l}\text { Participation in societal decision-making } \\
\text { processes }\end{array}$ \\
\hline & Autonomous self-support & Sustainable use of the environment as a sink & $\begin{array}{l}\text { Conservation of the cultural heritage and of } \\
\text { cultural diversity }\end{array}$ \\
\hline & $\begin{array}{l}\text { Just distribution of chances for using natural } \\
\text { resources }\end{array}$ & Avoidance of unacceptable technical risks & Conservation of nature's cultural functions \\
\hline & $\begin{array}{l}\text { Compensation of extreme differences in } \\
\text { income and wealth }\end{array}$ & $\begin{array}{l}\text { Sustainable development of real, human and } \\
\text { knowledge capital }\end{array}$ & Conservation of 'social resources' \\
\hline
\end{tabular}

conflicts, each rule can be valid only within the limits set by the others. Additionally, the concept includes a weighing principle by distinguishing between a core scope for each rule which always has to be fulfilled and may not be weighed against other rules, and a rather peripheral scope where weighing is possible. Regarding for instance the rule 'Ensuring satisfaction of basic needs', the core scope would be the pure survival of everyone, whereas the peripheral scope would have to be defined to a certain extent according to particular regional contexts.

The conflict potential included in the sustainability rules shows that even an integrative concept is not harmonistic. Rather, the integrative nature of sustainability increases the number of relevant conflicts. This approach is able to uncover those - otherwise hidden - conflicts in defining and implementing sustainable development. Thus, conflicts are by no means to be avoided but rather are at the heart of any activities to make sustainability work [15]. Rational conflict management and deliberation are, therefore, of great importance.

Sustainable development remains a political and normative notion also in the scientific attempts of clarifying and operationalisation. Therefore, it will not be possible to provide a kind of 'algorithm' for sustainability assessments allowing for calculating an objective 'one best solution' of sustainability challenges. What can be done, however, is to clarify the framework for assessments and societal decision making to support transparent, wellinformed and normatively orientated societal processes of deliberation on sustainability (Table 2).

\section{Sustainability principles for energy technology assessment}

The integrative sustainability concept has not been specifically developed as an instrument for technology assessment but refers to the development of society as a whole in the global perspective. However, technology is always just one component of societal relations and developments; many other and sometimes more relevant aspects - like patterns of production and consumption, lifestyles and cultural conventionalities, but also national and global political framework conditions - have to be considered to understand and assess societal developments. If the integrative sustainability concept is used as a normative framework for technology assessment, it has to be kept in mind that technology can only make (positive as well as negative) contributions to a sustainable development [16]. Moreover, these contributions always have to be seen against the background of other societal developments. Energy technologies as such are neither sustainable nor unsustainable but can only make more or less large contributions to sustainability - or cause problems.

First of all it has to be determined which rules of sustainability are relevant for technology assessment. This always has to be done regarding the technologies and the context under consideration. However, it is plausible to assume the following substantial rules being prima facie relevant in the energy context. Characteristic aspects of the relation of these rules to technology will be described in the following, including the wording of the rule (for a more detailed explanation see Kopfmüller et al. 2001 [12]).

\section{Protection of human health}

Dangers and intolerable risks for human health due to anthropogenically caused environmental impacts have to be avoided. Production, use and disposal of technology often have impacts which might negatively affect human health both in the short or long term. On the one hand, this includes accident hazards in industrial production (work accidents), but also in everyday use of technology (the large number of people injured or killed are a sustainability problem of motorised road traffic). On the other hand, there are also 'creeping' technology impacts which can cause harmful medium- or long-term effects by emissions into environmental media. The history of the use of asbestos and its devastating health effects are a particular dramatic example from the working 
Table 2 The instrumental principles of sustainability

\begin{tabular}{|c|c|}
\hline Instrumental rule & Explanation \\
\hline $\begin{array}{l}\text { Internalisation of external social and } \\
\text { environmental costs }\end{array}$ & Prices have to reflect the external environmental and social costs arising through the economic process. \\
\hline Adequate discounting & Neither future nor present generations should be discriminated through discounting. \\
\hline Debt & $\begin{array}{l}\text { In order to avoid restricting the state's future freedom of action, its current consumption expenditures } \\
\text { have to be financed, as a matter of principle, by current income. }\end{array}$ \\
\hline Fair international economic relations & $\begin{array}{l}\text { International economic relations have to be so organised that fair participation in the economic process is } \\
\text { possible for economic actors of all nations. }\end{array}$ \\
\hline $\begin{array}{l}\text { Encouragement of international } \\
\text { cooperation }\end{array}$ & $\begin{array}{l}\text { The various actors (government, private enterprises, non-governmental organisations) have to work } \\
\text { together in the spirit of global partnership with the aim of establishing the prerequisites for the initiation } \\
\text { and realisation of sustainable development. }\end{array}$ \\
\hline Society's ability to respond & $\begin{array}{l}\text { Society's ability to react to problems in the natural and human sphere has to be improved by means of } \\
\text { the appropriate institutional innovations. }\end{array}$ \\
\hline Society's reflexivity & $\begin{array}{l}\text { Institutional arrangements have to be developed, which make a reflection of options of societal action } \\
\text { possible, which extend beyond the limits of particular problem areas and individual aspects of problems. }\end{array}$ \\
\hline Self-management & Society's ability to lead itself in the direction of futurable development has to be improved. \\
\hline Self-organisation & The potentials of societal actors for self-organisation have to be increased. \\
\hline Balance of power & $\begin{array}{l}\text { Processes of opinion formation, negotiation and decision making have to be organised in a manner } \\
\text { which distributes fairly the opportunities of the various actors to express their opinions and to take } \\
\text { influence, and makes the procedures employed to this purpose transparent. }\end{array}$ \\
\hline
\end{tabular}

environment [17]. In the field of energy supply we have to mention in particular: accidents during the extraction of raw materials for energy, especially in coal mining, health risks from emissions in road traffic (e.g. diesel exhausts), especially in megacities, but also the hardly ever discussed problem of numerous deaths due to emissions from fireplaces for cooking and heating in living rooms in developing countries.

\section{Securing the satisfaction of basic needs}

A minimum of basic services (accommodation, nutrition, clothing, health) and the protection against central risks of life (illness, disability) have to be secured for all members of society. Technology plays an outstanding role in securing the satisfaction of basic human needs through the economic system; energy supply is also essential for this. This applies directly for the production, distribution and operation of goods to satisfy the needs (e.g. technical infrastructure for the supply of water, energy, mobility, and information, waste and sewage disposal, building a house, household appliances). However, this is on the one hand opposed by numerous negative impacts resulting from this way of need satisfaction common in industrialised countries (which then show up against the background of other sustainability rules). On the other hand, it has to be kept in mind that a large part of the world population is still cut off from this basic satisfaction of needs secured by means of technology. For example, approximately two billion people do not have access to a regular energy supply.

\section{Autonomous self-support}

All members of society have to be given the chance to ensure their economic existence including the possibility of children's education and preparing for ageing by voluntarily chosen activities. Sustainable development must include the best possible preparation for individuals to plan their lives themselves in an active and productive manner. The minimum prerequisite for this empowerment is that all members of society have the opportunity to secure an adequate and stable existence, including the education of children and provision for old age, by means of an occupation chosen of their own free will. This rule, formulated according to Sen [18], is directed at the presuppositions for a self-determined life. Technology often decides about the economic relations and about the possibilities to realise this principle. For instance, the field of using biomass for energetic purposes sometimes is closely related with ensuring the possibility of autonomous self-support of farmers and with the economic sustainability of the countryside.

\section{Just distribution of chances for using natural resources}

Taking use of environmental resources has to be distributed according to principles of fairness and justice (interand intragenerationally) and has to be decided by participatory procedures involving all people affected. Providing the basis for an independent livelihood presupposes, in its turn, that access to the necessary resources is assured. A necessary condition for this purpose is a just distribution of the opportunities for making use of the globally accessible environmental goods (the earth's atmosphere, the oceans, water, biodiversity, etc.) with the fair participation of all concerned. Currently this rule is by far not fulfilled in the consumption of energy 
resources. About two billion people do not have access to regular energy services at all.

\section{Sustainable use of renewable resources}

The usage rate of renewable resources must neither exceed their replenishment rate nor endanger the efficiency and reliability of the respective ecosystem. Renewable natural resources are, e.g. renewable energies (wind, water, biomass, geothermal energy, solar energy), ground water, biomaterials for industrial use (e.g. wood for building houses) and wildlife or fish stock. In the historical development of the concept of sustainability the rule on renewable resources has played a major role in the context of forestry and fishery. It contains two statements. On the one hand, it is essential that resources are extracted in a gentle way to protect the inventory. Human usage shall not consume more than can be replenished. On the other hand, it has to be ensured that the respective ecosystems are not overstrained, e.g. by emissions or serious imbalances. Here technology plays an important role in using the extracted resources as efficient as possible (e.g. energetic use of biomass) and minimising problematic emissions.

\section{Sustainable use of non-renewable resources}

The reserves of proven non-renewable resources have to be preserved over time. The consumption of non-renewable resources like fossil energy carriers or certain materials calls for a particularly close link to technology and technological progress. The consumption of non-renewable resources may only be called sustainable if the temporal supply of the resource does not decline in the future. This is only possible if technological progress allows for such a significant increase in efficiency of the consumption in the future that the reduction of the reserves imminent in the consumption does not have negative effects on the temporal supply of the remaining resources. So a minimum speed of technological progress is supposed. The rule of reserves directly ties in with efficiency strategies of sustainability; it can be really seen as a commitment to increase efficiency by technological progress and respective societal concepts of use for the consumption of non-renewable resources. One alternative, which also depends on the crucial contributions of technological concepts, would be substituting nonrenewable resources in production and use of technology with renewable ones (e.g. the reorganisation of the energy supply for transport from mineral oil to electricity from regenerative sources).

\section{Sustainable use of the environment as a sink}

The release of substances must not exceed the absorption capacity of the environmental media and ecosystems. Extraction of natural resources, processing of materials, energy consumption, transports, production processes, manifold forms of use of technology, operation of technical plants and disposal processes produce an enormous amount of material emissions which are then released into the environmental media water (ground water, surface water and oceans), air, and soil. These processes often cause serious regional problems, especially concerning the quality of air, ecosystems, biodiversity and freshwater. Technology plays a major role in all strategies for solving these problems. On the one hand, as an 'end-of-pipe' technology, it can reduce the emissions at the end of technical processes, e.g. in form of carbon capture and storage. On the other hand and this is the innovative approach, technical processes can be designed in a way that unwanted emissions do not occur at all. This requirement usually results in a significant need for research and development which even extends to basic research.

\section{Avoidance of unacceptable technical risks}

Technical risks with potentially disastrous impacts for human beings and the environment have to be avoided. This rule refers to three different categories of technical risks: (1) risks with comparatively high occurrence probability where the extent of the potential damage is locally or regionally limited, (2) risks with a low probability of occurrence but a high risk potential for human beings and the environment, (3) risks that are fraught with high uncertainty since neither the possibility of occurrence nor the extent of the damage can currently be sufficiently and adequately estimated. This rule is closely linked to the precautionary principle [19]. It could be applied to the problems discussed in the context of a severe nuclear reactor accident (worst-case scenario), for securing the long-term safety of a final repository for highly radioactive waste, or possible risks of the release of genetically modified organisms.

\section{Conservation of nature's cultural functions}

Cultural and natural landscapes or parts of landscapes of particular characteristic and beauty have to be conserved. A concept of sustainability only geared towards the significance of resource economics of nature would ignore additional aspects of a 'life-enriching significance' of nature. The normative postulate to guarantee similar possibilities of need satisfaction to future generations like the ones we enjoy today can therefore not only be restricted to the direct use of nature as a supplier of raw materials and sink for harmful substances but has to include nature as a subject of sensual, contemplative, spiritual, religious and aesthetic experience. Within the energy context, one has to be reminded of the final repository for radioactive waste at Yucca Mountain in the USA, where problems occurred due to the spiritual 
meaning of the region to the indigenous population. Also, the changing landscapes due to wind farms are a problem in some regions; this is discussed not only in connection with tourism but also regarding the aesthetic values of landscapes.

\section{Participation in societal decision-making processes}

All members of society must have the opportunity to participate in societally relevant decision-making processes. Regarding technology, this rule has a substantial and a procedural aspect (see in general Joss and Belucci [20]). On the one hand (substantially), it affects the design of technologies which (might) be used for participation. Here, the rule calls for exploiting these potentials of participation as far as possible. On the other hand (procedurally), the rule aims at the conservation, extension and improvement of democratic forms of decision making and conflict resolution, especially regarding those decisions which are of key importance for the future development and shaping of the (global) society; the aspect of designing future energy systems is definitely part of this. Future energy supply, far-reaching ethical questions of biomedical sciences with probably significant cultural impacts, questions of risk acceptance and acceptability in the case of genetically modified food are examples for technological developments with a considerable sustainability relevance which should be - according to this rule - dealt with participative methods.

\section{Equal opportunities}

All members of society must have equal opportunities regarding access to education, information, occupation, office, as well as social, political and economic positions. The free access to these goods is seen as a prerequisite for all members of society to have the same opportunities to realise their own talents and plans for life. This rule primarily relates to questions of societal organisation where technology only plays a minor role. However, the availability of energy is often a crucial precondition for being able to participate in societal processes at all, e.g. for having access to information and communication technologies which need energy or mobility which is also impossible without energy. The fact that approximately two billion people in the world do not have access to a regular energy supply underlines the circumstance that this also considerably restricts their possibilities of participation

Sustainability rules cannot be directly transferred into guidelines for technology design or even performance characteristics for technology. They do not refer to technological requirements but to aspects of society's economic behaviour where technology is just one aspect among others. If the consequences for technology are in the focus, the context has to be taken into consideration: which are the problems relevant for sustainability in the respective field, which technological and which societal conditions apply, how are they connected and how does the whole (and often quite complex) structure relate to the approach of the whole system of sustainability rules. So the sustainability rules have by no means a prescriptive character for technology design. A number of steps of transfer and mediation have to be done on the way from normative orientation to concrete technology design. This task cannot be in the sole responsibility of the people involved in technology development. In particular cases, societal dialogues are necessary and, where appropriate, even political decisions. Exactly this situation, where the system of sustainability rules provides orientation without determining technology in detail, supports the theory that the sustainability postulate is suitable as Leitbild for technology design. However, there are - and this will be discussed in the following sometimes considerable conceptual and methodological challenges.

\section{Case study: sustainability assessment of energy production from grassland}

The integrative sustainability concept has been applied to date in various project and consultancy activities in different thematic and regional contexts [21,22]. Among these is the analysis of grassland in the state of BadenWuerttemberg in Germany as a potential source of delivering local bioenergy. The background of this project is that in many regions of Germany and Europe, grassland shapes the cultural landscape and provides important functions in livestock farming as well as ecosystem services such as preserving biodiversity and protecting soil and water. The traditional use of grassland for forage production however is vanishing due to a declining number of cattle attributed to progresses in breeding and milk production as well as structural adaptations in agriculture. Dairy production continues to follow a trend towards increased intensification on a smaller number of larger, more specialised production units [23]. On the other hand, the demand for bioenergy and agricultural land to produce energy crops is rising due to political goals and measures to increase the regional supply of renewable energy [24]. Against this background, the integrative sustainability concept was applied to assess the sustainability performance of different processes and technologies to generate energy from maintained as well as converted grassland [25].

The application of the integrative sustainability concept in this context is based on three objectives: (1) the use of selected indicators to describe and assess the sustainability performance of the processes and technologies under investigation, (2) the comparison and 
evaluation of these processes and technologies to provide scientific support for decision makers and (3) the identification of conflicting sustainability goals or interests.

The adaptation of the integrative sustainability concept to the context of the project with its scientific and political enquiries implicated first the identification of the most relevant principles of sustainable development (see "The integrative approach to sustainable development" and "Sustainability principles for energy technology assessment" sections) as well as of suitable indicators. The instrumental principles, describing the necessary framework conditions for the realisation of the substantial minimum conditions listed in Table 2 were excluded because they are addressing issues beyond the scope of the project. Furthermore, the principles which apply to various societal areas have being ruled out due to the lack of significant correlation to the environment and technology-oriented project and in order to come up with a limited number of principles which can be handled within the time and resource frame of the project. The seven substantial sustainability principles which have been considered to be most relevant and realisable in the context of the project are listed in Table 3. Not surprisingly, they have an emphasis on maintaining society's productive potential and securing human existence.

In order to utilise these sustainability targets, 16 indicators have been identified to be appropriate to measure and assess the sustainability performance of the investigated processes and technologies. The selection is responding primarily to data availability and a range of inadequacies. Consequently, the set of indicators is neither perfectly consistent with the initial proposition nor fully developed in terms of the complexities of systemic interactions. However, for each of the seven relevant principles of sustainable development at least one suitable indicator could be identified (see Table 3). Thus, a balanced set of indicators was defined and applied to identify the sustainability chances and challenges of energy production from grassland.

Where possible, targets were identified for the selected indicators for distance-to-target considerations comparing current indicator values with targets. These targets were either adopted - in the case of already existing political decisions - or chosen in view of current debates. Based on the set of indicators, the sustainability rating of different processes and technologies to generate electricity and heat from maintained or converted grassland described in Table 4 was analysed.

The results of the indicator-based sustainability assessment are summarised in Table 5. In order to increase the comprehensibility and comparability, the indicatorspecific results have been transformed into a qualitative evaluation system by comparing the results with the reference system 'fossil energy production and mulching of the grassland'. Plus $(+)$ and minus $(-)$ indicate whether the process has positive or negative impacts compared with the reference value. Additionally, the results of the processes were numbered from 1 to 9 for each indicator to indicate their position among the processes analysed. The score of ' 1 ' indicates the best performance with regard to the sustainability indicator in comparison with the other process chains, and the score of ' 9 ' illustrates that this process is the furthest away

Table 3 Application of the integrated concept of sustainable development in the grassland project: selection of relevant principles and indicators

\begin{tabular}{ll}
\hline Substantial principles of sustainability (see Table 1) & Indicators \\
\hline Protection of human health & Emissions of particulate matter \\
& Emissions of $\mathrm{NO}_{x}$ \\
& Emissions of $\mathrm{CO}$ \\
& Emissions of substances producing summer smog \\
& Emissions of fungal spores \\
Autonomous self-support & Agricultural employment \\
& Income opportunities for farmers \\
Just distribution of chances for using natural resources & Emissions of greenhouse gases \\
Sustainable use of renewable resources & Preservation of biodiversity \\
& Conservation of soil \\
Sustainable use of non-renewable resources & Protection of ground and surface water \\
Sustainable use of the environment as a sink & Substitution of non-renewable resources \\
& Greenhouse gas reduction costs \\
Conservation of nature's cultural functions & Emissions affecting eutrophication \\
& Emissions affecting acidification \\
\end{tabular}


Table 4 Investigated processes for energy production from grassland

\begin{tabular}{|c|c|c|c|}
\hline Nature of grassland & $\begin{array}{l}\text { Type of biomass and yield (dry matter per } \\
\text { hectare and year) }\end{array}$ & Product or process & Label \\
\hline \multirow{5}{*}{$\begin{array}{l}\text { Maintained extensive grassland (low } \\
\text { productivity) }\end{array}$} & Mulching & Reference grassland use & \\
\hline & Hay $(3.9$ t) & High pressure (HP) bales (REKA) & A \\
\hline & & Round bales (Herlt) & B \\
\hline & & Pellets (Agroflamm) & C \\
\hline & & Dry fermentation with maize silage & $\mathrm{D}$ \\
\hline Converted extensive grassland & Short rotation poplars (5.6 t) & Wood chips & $E$ \\
\hline \multirow{4}{*}{$\begin{array}{l}\text { Maintained intensive grassland (high } \\
\text { productivity) }\end{array}$} & Grass silage, two cuts per year (6.4 t) & Wet fermentation & $\mathrm{F}$ \\
\hline & & Wet fermentation with substrate mix & $\mathrm{F}$ \\
\hline & Grass silage, three cuts per year (10 t) & Wet fermentation & $\mathrm{F}$ \\
\hline & & Wet fermentation with substrate mix & $\mathrm{F}$ \\
\hline \multirow[t]{5}{*}{ Converted intensive grassland } & Maize (15 t) & Wet fermentation & G \\
\hline & & Wet fermentation with substrate mix & G \\
\hline & & Dry fermentation with hay & $\mathrm{D}$ \\
\hline & Short rotation poplars (9.4 t) & Wood chips & $\mathrm{H}$ \\
\hline & & $\begin{array}{l}\text { Wood chips (low emissions } \\
\text { combustion) }\end{array}$ & । \\
\hline
\end{tabular}

from contributing to achieve the specific sustainable target.

A further aggregation of the indicator-based results with methods such as the monetary valuation of environmental burden was not pursued because the weighing method is difficult with regard to the availability of data, e.g. avoidance costs or loss expenses. Ranking sustainability indicators is an alternative way of

Table 5 Results of the sustainability assessment of the grassland project

\begin{tabular}{|c|c|c|c|c|c|c|c|c|c|}
\hline \multirow{2}{*}{$\begin{array}{l}\text { Type of grassland } \\
\text { Process }\end{array}$} & \multicolumn{5}{|c|}{ Extensive } & \multicolumn{4}{|c|}{ Intensive } \\
\hline & A & B & C & D & $\mathrm{E}$ & $\mathrm{F}$ & G & H & 1 \\
\hline \multicolumn{10}{|l|}{ Sustainable use of non-renewable resources } \\
\hline Primary energy yield & $++(7)$ & $++(6)$ & $++(5)$ & $++(8)$ & $++(3)$ & $++(4)$ & $++(2)$ & $++(1)$ & $++(1)$ \\
\hline \multicolumn{10}{|l|}{ Sustainable use of the environment as a sink } \\
\hline Greenhouse gas emissions & $++(6)$ & $++(5)$ & $++(4)$ & $+(8)$ & $++(2)$ & $++(7)$ & $++(3)$ & $++(1)$ & $++(1)$ \\
\hline Cost of avoiding greenhouse gas emissions & $-(5)$ & $-(3)$ & - (3) & - - (6) & $+(2)$ & - - (4) & - - (4) & $++(1)$ & $++(1)$ \\
\hline Emissions leading to eutrophication & $-(5)$ & $0(3)$ & $-(6)$ & - - (9) & $0(2)$ & - - (8) & - - (7) & $0(3)$ & $0(1)$ \\
\hline Emissions leading to acidification & $-(5)$ & $0(4)$ & $-(6)$ & - - (9) & $+(3)$ & - - (8) & - - (7) & $+(2)$ & $+(1)$ \\
\hline \multicolumn{10}{|l|}{ Protection of human health } \\
\hline Emissions of particulate matter & $0(4)$ & $-(7)$ & $-(5)$ & $+(1)$ & $-(8)$ & $0(2)$ & $0(3)$ & - - (9) & $-(6)$ \\
\hline NOx emissions & $--(7)$ & - - (6) & - - (8) & $+(1)$ & $-(4)$ & $-(3)$ & $-(5)$ & - - (6) & $-(2)$ \\
\hline CO emissions & - - (9) & $+(2)$ & $0(3)$ & $0(4)$ & $-(6)$ & $-(5)$ & - - (7) & - - (8) & $+(1)$ \\
\hline Emissions of substances producing summer smog & - - (8) & $-(7)$ & - - (9) & $+(1)$ & $-(4)$ & $-(3)$ & $-(5)$ & $-(6)$ & $0(2)$ \\
\hline Emissions of fungal spores & 0 & 0 & 0 & - & - & 0 & 0 & - & - \\
\hline \multicolumn{10}{|l|}{ Sustainable use of renewable resources } \\
\hline Preservation of biodiversity & $+(1)$ & $+(1)$ & $+(1)$ & $+(1)$ & $-(4)$ & $0 /-(2)$ & - - (5) & $0(3)$ & $0(3)$ \\
\hline Conservation of soil & $0(1)$ & $0(1)$ & $0(1)$ & $0(1)$ & $-(2)$ & $0(1)$ & - - (3) & $-(2)$ & $-(2)$ \\
\hline Protection of the ground and surface water & $0(1)$ & $0(1)$ & $0(1)$ & $0(1)$ & $-(2)$ & $0(1)$ & - - (3) & $-(2)$ & $-(2)$ \\
\hline \multicolumn{10}{|l|}{ Conservation of nature's cultural function } \\
\hline Alteration of the cultural landscape & $+(1)$ & $+(1)$ & $+(1)$ & $+(1)$ & $-/+(2)$ & $+(1)$ & $-(3)$ & $-/+(2)$ & $-/+(2)$ \\
\hline \multicolumn{10}{|l|}{ Autonomous self-support } \\
\hline Agricultural employment & $+(1)$ & $+(4)$ & $+(8)$ & $+(7) f$ & $+(6)$ & $+(5)$ & $+(2)$ & $+(3)$ & $+(3)$ \\
\hline Income opportunities for farmers & $-(7)$ & $+(5)$ & $-(8)$ & $+(6) f$ & $++(2)$ & $+(4)$ & $+(3)$ & $++(1)$ & $++(1)$ \\
\hline
\end{tabular}

$\mathrm{f}$ - The data given apply to co fermentation of hay from extensive grassland and maize silage 
summarising the results. However, this process cannot be carried out by scientists alone, but needs a stakeholder and citizens' dialogue contributing to broad consensus in society and politics. For this reason as well as to retain a high degree of transparency in presenting the outcomes of the study, the results of the sustainability assessment are presented in single results.

The overall result of the sustainability assessment is not surprising - that all processes analysed have both advantages and disadvantages and that the evaluation relies on the reference scenario (mulching or dairy farming) applied. However, all processes reveal benefits in terms of saving non-renewable energy and reducing greenhouse gas emissions, but only short rotation poplars in suitable locations can reduce costs to a level that is competitive with current costs for EU emission certificates for $\mathrm{CO}_{2}$. Processes based on the maintenance of grassland are resulting in sustainability advantages with respect to the preservation of biodiversity and nature's cultural landscape as well as the protection of soil and groundwater. An impact on agricultural employment can be reached with all processes investigated, which is high compared with mulching, but quite low compared with labour-intensive milk production. Despite the financial support for bioenergy, the effects of energy production from grassland on agricultural employment and farmers' income are modest and not sufficient to secure autonomous self-support.

Negative impacts on sustainable development result from the conversion of grass or energy crops into electricity and heat due to the associated increase in emissions, which lead to acidification, eutrophication and risks to human health. The sustainability assessment indicates that short rotation poplars are comparatively advantageous from the economic and ecological point of view. In the future, innovative techniques to convert grass rich in lignocellulose into biofuels (e.g. biomass ethanol or biomass synfuel) could open up further options for a sustainable use of grassland. Such biofuels derived from low-input, high-diversity mixtures of native grassland perennials can provide more usable energy, greater greenhouse gas reductions and less emission than solid biofuels and less agrochemical pollution per hectare than corn grain ethanol or rapeseed biodiesel.

It can be concluded that an evaluation of the results from the sustainability assessment by politics and society is needed because none of the investigated processes perform best on all sustainability indicators selected. If the emphasis of sustainable development is on renewable energy and climate protection, short rotation poplars will be the best choice. However, if the maintenance of grassland for conserving biodiversity and nature's cultural landscape has highest priority, the process of hay combustion would be the preferred choice. The results from the stakeholder workshops conducted in the project emphasise this statement with the message 'In the light of conflicting sustainability interests, society has to decide which sustainability target is more important'.

Meanwhile, various stakeholder groups have undertaken a wide range of initiatives as steps towards the development of sustainability standards and biomass certification systems. Between them, there seems to be a general agreement that it is important to include economic, social and environmental criteria in the development of a biomass certification system. However, mutual differences are also visible in the strictness, extent and level of detail of these criteria, due to various interests and priorities. Concrete initiatives to translate these standards into operational criteria and indicators and to monitor and verify them through an established biomass certification system are more limited.

One consequence of the widely acknowledged need to secure the sustainability of biomass production in a fast growing market is the Renewable Energy Directive 2009/28/EC of the European Union (EU-RED) which includes a set of mandatory sustainability criteria and targets as part of an EU sustainability scheme [26] and in the Fuel Quality Directive 2009/30/EC [27]. In this context, biofuels are required to fulfil all sustainability criteria to count towards EU targets and to be eligible for financial support. The EU-RED excludes several land categories, with recognised high biodiversity value, from being used for biofuel production including highly biodiverse grassland, either natural or non-natural. That means that politicians have decided that in the case of conflicting targets in the use of grassland for energy production, the conservation of grassland with high biodiversity has a higher priority than the provision of renewable energy for example by establishing high-yield short rotation coppice.

\section{Conclusions}

The integrative approach to understand sustainability per definition without hastily reducing it to merely ecological aspects has proven the richness of the spectrum of aspects of sustainability in the energy sector. Of course, criteria of resource economics and ecology are of special importance. But also questions of participation, autonomous self-support and equal opportunities; the way to deal with technical risks and aesthetic values of landscapes; the shaping of reflexive societal decision processes and the modelling of economic framework conditions as well as aspects of human health play crucial roles involving, for example, also social science by necessity [28]. Compared with this result, it has to be noted that the sustainability debate on energy questions in industrial countries is often narrowed, reduced to 
questions of security of supply and compatibility with the environment or the climate, at the utmost supplemented by aspects of economic development or social peace. In contrast, it has to be pointed out: The sustainability of energy technologies is measured against a much larger spectrum of principles, criteria and indicators than often assumed.

However, this spectrum aggravates the well-known problems of prospective sustainability assessment. Especially with regard to unavoidable conflicts of objective between the different criteria of sustainability and the incommensurability of many criteria, the need for a methodologically secured approach of sustainability assessment is obvious. Classical instruments like life cycle assessment or simulations are required, but by no means sufficient. On the one hand, they have to be developed further to meet the range of sustainability criteria. Approaches like consequential life cycle assessment (LCA) or social LCA veer towards this, but are of course just starting off. On the other hand, qualitative procedures of deliberation for 'soft' criteria of sustainability and for the consideration of conflicts of objectives are necessary. The concept introduced in this paper does not solve these methodological problems; but nevertheless it provides a well-founded conceptual framework for the further development of these methods of assessment on a transparent basis.

\section{Authors' contributions}

AG drafted the general description of the integrated concept of sustainable development. CR designed and carried out the case study sustainability assessment of energy production from grassland. Both authors read and approved the final manuscript.

\section{Competing interests}

The authors declare that they have no competing interests.

Received: 5 October 2011 Accepted: 21 November 2011

Published: 21 November 2011

\section{References}

1. WCED - World Commission on Environment and Development (1987) Our common future. Oxford, New York

2. Grunwald A, Kopfmüller J (2006) Nachhaltigkeit. Eine Einführung. Campus, Frankfurt a. Main

3. UN-ECOSOC - United Nations-Economic and Social Council (2000) Energy and sustainable development: key issues. Preparation for the ninth Session of the Commission on Sustainable Development by the Intergovernmental Group of Experts on Energy and Sustainable Development; Document Nr. E/CN.17/ESD/2000/3, New York 2000

4. IEA-WEO (2008) World Energy Outlook 2008. IEA Publications, Paris

5. von Schomberg R (2002) The objective of sustainable development: are we coming closer? EU Foresight Working Papers Series 1, Brussels

6. Scrase I, Mackerron G, (eds) (2009) Energy for the future: a new agenda. Palgrave Macmillan, New York

7. Grunwald A (2009) Technology assessment: concepts and methods. In: Meijers A (ed) Philosophy of technology and engineering sciences, vol 9. Elsevier, Amsterdam, pp 1103-1146

8. Brown N, Rappert B, Webster A, (eds) (2000) Contested futures. A sociology of prospective techno-science. Ashgate, Burlington
9. Grunwald A (2008) Working towards sustainable development in the face of uncertainty and incomplete knowledge. J Environ Pol Plann 9(3):245-262

10. IIASA - International Institute for Applied Systems Analysis (2007) A proposal for a global energy assessment. Laxenburg, Austria

11. Nakicenovic N, Kolp P, Riahi K, Kainuma M, Hanaoka T (2006) Assessment of emission scenarios revisited. Environ Econ Pol Stud 7(3):137-173

12. Kopfmüller J, Brandl V, Jörissen J, Paetau M, Banse G, Coenen R, Grunwald A (2001) Nachhaltige Entwicklung integrativ betrachtet. Konstitutive Elemente, Regeln, Indikatoren. Berlin

13. Kopfmüller J, (ed) (2006) Ein Konzept auf dem Prüfstand. Das integrative Nachhaltigkeitskonzept in der Forschungspraxis. Berlin: edition sigma

14. Brown-Weiss E (1989) In fairness to future generations. International law, common patrimony and intergenerational equity. Transnational Publishers, New York

15. Grunwald A (2005) Conflicts and conflict-solving as chances to make the concept of sustainable development work. In: Wilderer PA, Schroeder ED, Kopp H (eds) Global sustainability. The impact of local cultures. a new perspective for science and engineering, economics and politics. Wiley-VCH, Weinheim pp 107-122

16. Weaver P, Jansen L, van Grootveld G, van Spiegel E, Vergragt P (2000) Sustainable technology development. Greenleaf Publishing, Sheffield

17. Gee D, Greenberg M (2002) Asbestos: from 'magic' to malevolent mineral. In: Harremoes P, Gee D, MacGarvin M, Stirling A, Keys J, Wynne B, Guedes $\operatorname{Vaz} S$ (eds) The precautionary principle in the 20th century. Late lessons from early warnings. Sage, London pp 49-63

18. Sen A (1998) Ausgrenzung und Politische Ökonomie. Zeitschrift für Sozialreform 44(4-6):234-247

19. von Schomberg R (2005) The precautionary principle and its normative challenges. In: Fisher E, Jones J, von Schomberg R (eds) The precautionary principle and public policy decision making. Cheltenham, UK; Northampton, MA pp 141-165

20. Joss S, Bellucci S (2002) Participatory technology assessment in Europe: introducing the EUROPTA research project. In: Joss S, Bellucci S (eds) Participatory technology assessment. European perspectives. Centre for the Study of Technology, Westminster pp 3-14

21. Kopfmüller J, Lehn H, Nuissl H, Krellenberg K, Heinrichs D (2009) Sustainable development of megacities - an integrative research approach for the case of Santiago de Chile. Erde 140(4):417-448

22. Schulz J, Brand F, Kopfmüller J, Ott K (2008) Building a "Theory for Sustainable Development". Two salient conceptions within the German discourse. Int J Environ Sustain Dev 7(4):465-482

23. van Arendonk JAM, Liinamo A-E (2003) Dairy cattle production in Europe. Theriogenology 59(2):563-569

24. Büsgen U, Dürschmidt W (2009) The expansion of electricity generation from renewable energies in Germany: a review based on the Renewable Energy Sources Act Progress Report 2007 and the new German feed-in legislation. Energ Pol 37(7):2536-2545

25. Rösch Ch, Skarka J, Raab K, Stelzer V (2009) Energy production from grassland - assessing the sustainability of different process chains under German conditions. Biomass and Bioenergy 33(4):689-700

26. EC European Commission (2009) Directive 2009/28/EC of the European Parliament and of the Council of 23 April 2009 on the promotion of the use of energy from renewable sources and amending and subsequently repealing Directives 2001/77/EC and 2003/30/EC.

27. EC European Commission (2009) Directive 2009/30/EC of the European Parliament and of the Council of 23 April 2009 amending Directive 98/70/ $\mathrm{EC}$ as regards the specification of petrol, diesel and gas-oil and introducing a mechanism to monitor and reduce greenhouse gas emissions and amending Council Directive 1999/32/EC as regards the specification of fuel used by inland waterway vessels and repealing Directive 93/12/EEC

28. Rohracher $\mathrm{H}$ (2008) Energy systems in transition: contributions from social sciences. Int J Environ Tech Manag 9(2/3):144-161

\section{doi:10.1186/2192-0567-1-3}

Cite this article as: Grunwald and Rösch: Sustainability assessment of energy technologies: towards an integrative framework. Energy,

Sustainability and Society 2011 1:3. 